\title{
Evidence from plasma progesterone concentrations for male-induced ovulation in the brush-tailed bettong, Bettongia penicillata
}

\author{
L. A. Hinds ${ }^{1}$ and M. J. Smith ${ }^{2}$ \\ ${ }^{1}$ Division of Wildlife and Ecology, CSIRO, PO Box 84, Lyneham, 2602, ACT, Australia; and \\ ${ }^{2}$ Evolutionary Biology Unit, South Australian Museum, North Terrace, Adelaide,
}

South Australia, 5000

\begin{abstract}
Summary. Female brush-tailed bettongs, Bettongia penicillata, were housed with either an intact or vasectomized male or isolated from males in the peripartum period. Development of the quiescent corpus luteum formed at the post partum oestrus was initiated by removing the pouch young. Blood samples for analysis of plasma progesterone were collected from the females 2 days before removal of pouch young, daily for 5 or 6 days and then 2-3 times each week until 19 days after removal of pouch young.
\end{abstract}

Plasma progesterone profiles were similar in pregnant and nonpregnant cycles. There was an early progesterone peak $\left(1206 \pm 121 \mathrm{pg} \mathrm{ml}^{-1}\right.$, mean $\left.\pm \mathrm{SEM} ; n=16\right)$ between days 2 and 5 after removal of pouch young, and a second period of high concentrations $\left(>800 \mathrm{pg} \mathrm{ml}^{-1}\right)$ before birth on day $17 \cdot 4 \pm 0 \cdot 2(n=16)$. The interval between the early peak and birth was 14 or 15 days. On five of 34 occasions, no increases in plasma progesterone concentrations occurred after removal of pouch young.

On 12 of 15 occasions for 13 females that had been isolated from males post partum, plasma progesterone concentrations also remained low $\left(<100 \mathrm{pg} \mathrm{ml}^{-1}\right)$ and did not change after removal of pouch young. Females that showed no increases in plasma progesterone concentration after removal of pouch young had significantly lower $(P<0.001)$ plasma progesterone concentrations while lactating than those females that did undergo a cycle after removal of pouch young $\left(60 \pm 4 \mathrm{pg} \mathrm{m}^{-1}, n=17\right.$ and $225 \pm 23 \mathrm{pg} \mathrm{ml}^{-1}, n=30$, respectively). Females isolated from males post partum, and monitored until day 12 after removal of the pouch young, and that showed no increases in progesterone in this period, had ovaries that contained no corpus luteum, only corpora albicantia and numerous atretic or developing follicles.

We conclude that brush-tailed bettongs are induced ovulators, a characteristic described for only one other marsupial, Monodelphis domestica, from South America.

Kelwords: pregnancy; oestrous cycle; marsupial; brush-tailed bettong

\section{Introduction}

Among marsupials, induced ovulation has been described in only one South American marsupial, Monodelphis domestica (Fadem \& Rayve, 1985). In Australian marsupials that have been adequately studied, it has been assumed that ovulation is spontaneous (Tyndale-Biscoe \& Renfree, 1987). In this study, we present the first evidence for induced ovulation in an Australian marsupial.

In most species of the superfamily Macropodoidea (kangaroos, wallabies and rat-kangaroos), pregnancy occupies most of the oestrous cycle and birth is followed by post partum oestrus. 
Development of the newly formed corpus luteum is inhibited, directly or indirectly, by the sucking stimulus of the pouch young, as is the development of the embryo beyond the unilaminar blastocyst stage (Tyndale-Biscoe \& Renfree, 1987). Removal of the sucking stimulus permits reactivation of the corpus luteum and, if the female is pregnant, the blastocyst also undergoes renewed development.

The superfamily Macropodoidea comprises two families, the Macropodidae (kangaroos and wallabies) and the Potoroidae (rat-kangaroos). The patterns of change in plasma progesterone concentrations during reproductive cycles have been described for only three species of the family Macropodidae, the quokka, Setonix brachyurus (Cake et al., 1980), the tammar, Macropus eugenii (Hinds \& Tyndale-Biscoe, 1982; Tyndale-Biscoe et al., 1983), and Bennett's wallaby, Macropus rufogriseus rufogriseus (Walker \& Gemmell, 1983; Curlewis et al., 1987). In each of these species, the profile of progesterone concentration is bimodal during pregnancy; it is characterized by an early peak after removal of the sucking young and a rise in the second half of the oestrous cycle or pregnancy. The interval from removal of pouch young to the early peak is 5-6 days in the tammar (Hinds \& Tyndale-Biscoe, 1982), 3-4 days in the quokka (Cake et al., 1980) and 3-5 days in Bennett's wallaby (Walker \& Gemmell, 1983; Curlewis et al., 1987). The peak also occurs in nonpregnant tammars (Hinds \& Tyndale-Biscoe, 1982) and Bennett's wallabies (Curlewis et al., 1987), but was not observed in three nonpregnant quokkas (Cake et al., 1980). In the tammar, although the interval from removal of pouch young to the early peak may vary, the interval from the peak to birth is relatively constant at 21-22 days (Hinds \& Tyndale-Biscoe, 1982; Tyndale-Biscoe et al., 1986; Hinds, 1989a). This interval appears equally consistent in the Bennett's wallaby and quokka, but cannot be determined precisely from the literature (Cake et al., 1980; Walker \& Gemmell, 1983; Curlewis et al., 1987).

The pattern of changes in plasma progesterone concentrations during the reproductive cycle has not been described for any species within the family Potoroidae, with the exception of a brief mention in Rose (1989) of unpublished results for two Bettongia gaimardi. Only one of these females showed an early progesterone peak on day 3 after removal of pouch young, but both had high concentrations before parturition. We studied the potoroid, Bettongia penicillata, which weighs $0.9-1.3 \mathrm{~kg}$, breeds throughout the year and is monovular and polyoestrous (Parker, 1977). The gestation period is 21 days, and the length of the oestrous cycle is 21-22 days (Smith, 1992). Plasma progesterone concentrations were determined in mated and unmated females.

\title{
Materials and Methods
}

\begin{abstract}
Animals
Animals were housed at the Evolutionary Biology Unit of the South Australian Museum, Gilles Plains, South Australia, where a colony of approximately $150 \mathrm{~B}$. penicillata is maintained. They were held in pens with a floor area of $48 \mathrm{~m}^{2}$. Breeding pens, occupied by one male and one to three females, were located either outdoors (aviary-type pens) or in a brick shed with natural light and uncontrolled temperature. Holding pens, occupied only by females, were in an insulated, galvanized iron shed with natural light and temperature maintained at $15-30^{\circ} \mathrm{C}$; at no time was a male older than 4 months housed in this shed. The animals' diet consisted of apples, bananas, bread, parrot seed mix, dry dog food, hard-boiled eggs and pellet-formed kangaroo ration (Milling Industries). Water was provided ad libitum. At least 2 days before parturition females were moved to a breeding pen, so that at post partum oestrus they would be associated with an intact or a vasectomized male. Subsequently when pouch young were more than 7 , but less than 50, days old, they were removed from the teat to induce reactivation of the corpus luteum. During the ensuing pregnant and nonpregnant cycles, blood samples for determination of plasma progesterone were obtained from a lateral tail vein. The day of removal of pouch young has been designated day 0 . Pouches were checked daily between 09:00 and 10:00 h from day 15 to day 20 after removal of pouch young to determine the day of birth of a new young.
\end{abstract}

\section{Experimental design}

A preliminary experiment was carried out to determine the presence or absence of an early progesterone peak in 13 females, all of which had been housed with an intact male post partum. Blood samples were taken from the animals 
under two sampling regimens; on days 0-5 after removal of pouch young $(n=7)$ and days -2 and 1-6 after removal of pouch young $(n=6)$.

For a further 14 cycles in which the females had previously been housed with an intact male, blood samples were taken on days $-2,1-5,8,11,15,17$ and 19 after removal of pouch young. For seven of eight females associated with a vasectomized male post partum, blood samples were collected on days $-2,1-5,8,10,12,15,17$ and 19 after removal of pouch young. For the remaining animal, no samples were taken after day 12 after removal of pouch young.

Of the 35 cycles monitored above, increases in plasma progesterone concentration were evident in 30 instances, but two animals housed with a vasectomized male and three animals housed with intact males in the previous post partum period showed no changes in progesterone concentration after removal of pouch young. To determine whether the presence of the male was essential for ovulation, at a subsequent post partum period, 13 females were isolated from males and blood samples collected on days $-2,1-5,8,11,15,17$ and 19 after removal of pouch young. Of this group, seven females had previously been monitored throughout a pregnancy and a known nonpregnant cycle. Another two females in the group were monitored until day 12 when they were killed to collect ovaries and uteri for histological examination.

\section{Collection of blood samples}

Blood samples $(1.5-2.0 \mathrm{ml})$ were taken, between $09: 00 \mathrm{~h}$ and $11: 00 \mathrm{~h}$, from a lateral tail vein using a 23 gauge needle and $2.0 \mathrm{ml}$ heparinized syringe. Each sample was placed on ice until it was centrifuged $(7000 \mathrm{~g})$ at $4^{\circ} \mathrm{C}$ for $10 \mathrm{~min}$. Plasma was stored at $-20^{\circ} \mathrm{C}$.

\section{Vasectomy}

Three male bettongs were vasectomized using a procedure similar to that previously described for the eastern quoll, Dasyurus viverrinus (Hinds, 1989b). Vasectomies were performed at least 4 weeks before the males were housed with any females used in this study.

\section{Histology}

Ovaries and uteri were fixed in Bouin's fixative or Lillee's neutral buffered formalin before being embedded in paraffin wax. Serial sections were cut at $8 \mu \mathrm{m}$ and stained with haematoxylin and eosin.

\section{Progesterone assay}

Plasma progesterone concentrations were determined by a radioimmunoassay described for the tammar wallaby (Sernia et al., 1980), and validated here for the bettong. Antiserum 9817, a gift from R. I. Cox (CSIRO Division of Animal Production, Sydney, Australia) was used at a final dilution of $\mathrm{t}: 224000$. Duplicate samples of plasma (100$250 \mu \mathrm{l}$ ) were measured. The sensitivity of the assay was $10 \mathrm{pg}$ per tube or $50 \mathrm{pg} \mathrm{ml}^{-1}$ plasma, and the hexane solvent blank and charcoal-treated (steroid-free) plasma blank always measured less than these limits. After extraction twice with freshly redistilled $n$-hexane the recovery of $\left[{ }^{3} \mathrm{H}\right]$ progesterone from plasma of several different bettongs was $97.2 \pm 0.8 \%$ (mean $\pm \mathrm{SD}, n=8$ ). The recovery of unlabelled progesterone added to charcoal-treated plasma was within $7 \%$ of that expected, while the intra- and interassay coefficients of variation were $7.5 \%(n=12)$ and $9.5 \%$ $(n=7)$, respectively. Serial dilutions $(25-250 \mu 1)$ of a pool of plasma collected from late-pregnant females were parallel to the progesterone standard curve. Plasma $(50-300 \mu \mathrm{l})$ from a juvenile male showed no displacement in the assay system. The addition of charcoal-treated plasma $(250 \mu \mathrm{l})$ had no effect on maximum binding ( $60 \%$ in both cases), and a standard curve prepared in charcoal-treated plasma superimposed over the progesterone standard curve prepared in buffer.

\section{Statistical analyses}

Student's $t$ tests were used to determine whether differences existed between paired parameters for each reproductive state. These parameters were the intervals from removal of pouch young to the early progesterone peak, and the concentrations of progesterone at different times through the cycle. Specific comparisons for the group of seven animals that had been housed with an intact or vasectomized male or isolated from males in the post partum period were also made.

A profile of progesterone concentrations included an early peak of progesterone and, where monitored, an increase after day 11 and a subsequent decrease after day 19 after removal of pouch young. On the basis of studies of progesterone concentrations in other members of the Macropodidae (see Introduction), this profile is deemed to represent a cycle irrespective of the reproductive status of the female. A nil response to removal of pouch young was indicated when plasma progesterone remained $<100 \mathrm{pg} \mathrm{ml}^{-1}$ throughout the sampling period. 


\section{Results}

Changes in plasma progesterone concentrations after removal of a pouch young were monitored in 23 individual females that had been in contact with either an intact or a vasectomized male or isolated from a male at the previous post partum period. For some of these contacts some females were monitored on more than one occasion (Tables 1 and 2).

Table 1. Summary of reproductive cycles monitored in Bettongia penicillata in response to removal of the pouch young

\begin{tabular}{llccc}
\hline & & \multicolumn{2}{c}{ Number of cycles } \\
\cline { 4 - 5 } $\begin{array}{l}\text { Type of male } \\
\text { present post partum }\end{array}$ & \multicolumn{1}{c}{ Cycle } & $\begin{array}{c}\text { Number of } \\
\text { females }\end{array}$ & $\begin{array}{c}\text { With progesterone } \\
\text { increase }\end{array}$ & $\begin{array}{c}\text { Without progesterone } \\
\text { increase }\end{array}$ \\
\hline Intact & Pregnant & $14^{\mathrm{a}}$ & 16 & 0 \\
Vasectomized & Failed pregnant & 10 & 8 & 3 \\
None & Nonpregnant & 8 & 6 & 2 \\
\hline
\end{tabular}

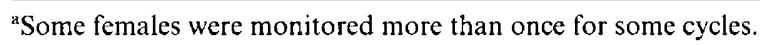

Table 2. Observations of subsequent reproductive events in response to removal of pouch young in seven female Bettongia penicillata associated with or without males post partum

\begin{tabular}{|c|c|c|c|c|c|c|c|}
\hline \multirow[b]{2}{*}{$\begin{array}{l}\text { Female } \\
\text { No. }\end{array}$} & \multicolumn{7}{|c|}{ Type of male associated with females in post partum period: } \\
\hline & $\begin{array}{l}\text { Interval to } \\
\text { progesterone } \\
\text { peak (days) }\end{array}$ & $\begin{array}{l}\text { Magnitude } \\
\text { of peak of } \\
\text { progesterone } \\
\left(\mathrm{pg} \mathrm{ml} \mathrm{ml}^{-1}\right)\end{array}$ & $\begin{array}{l}\text { Days } \\
\text { to } \\
\text { birth }\end{array}$ & $\begin{array}{l}\text { Interval to } \\
\text { progesterone } \\
\text { peak (days) }\end{array}$ & $\begin{array}{l}\text { Magnitude } \\
\text { of peak of } \\
\text { progesterone } \\
\left.(\mathrm{pg} \mathrm{ml})^{-1}\right)\end{array}$ & $\begin{array}{l}\text { Interval to } \\
\text { progesterone } \\
\text { peak (days) }\end{array}$ & $\begin{array}{c}\text { Magnitude } \\
\text { of peak of } \\
\text { progesterone } \\
\left(\mathrm{pg} \mathrm{ml} \mathrm{l}^{-1}\right)\end{array}$ \\
\hline 29 & 2 & 1380 & 16 & 4 & 939 & Nil & Nil \\
\hline 29 & 3 & 867 & $\mathrm{Nil}$ & & & & \\
\hline 43 & 5 & 1290 & 19 & 3 & 741 & Nil & Nil \\
\hline 43 & 3 & 896 & 18 & & & & \\
\hline 43 & 5 & 1370 & Nil & & & & \\
\hline 45 & 2 & 1453 & Nil & Nil & $\mathrm{Nil}$ & Nil & Nil \\
\hline 45 & 2 & 846 & 17 & & & & \\
\hline 56 & $3 \cdot 5$ & 1406 & 18 & 3 & 877 & Nil & Nil \\
\hline 72 & 3 & 1895 & 18 & 5 & 1576 & Nil & Nil \\
\hline 73 & 2.5 & 947 & 17 & 3 & 542 & Nil & Nil \\
\hline 77 & 2 & 1376 & Nil & 4 & 642 & Nil & Nil \\
\hline
\end{tabular}

Nil: observations made, but no events evident.

\section{Females associated with intact males in the post partum period}

In this group of 20 females, progesterone concentrations were determined either throughout the cycle or for the first 6 days after removal of pouch young. Pouch young were removed on 27 separate occasions and for 24 of these a clearly defined profile of progesterone concentration was seen. A neonate was detected in the pouch on 16 occasions (Fig. 1). A new pouch young was not observed for the remaining eight cycles which have been termed failed pregnancies, because it is unknown whether the animals failed to conceive in the post partum period or if the young was lost 
at parturition. For the remaining three animals, two of which had shown cycles when monitored previously, no changes in plasma progesterone concentrations occurred after removal of pouch young; concentrations remained low to undetectable $\left(<100 \mathrm{pg} \mathrm{ml}^{-1}\right)$. Where a distinct pattern of progesterone occurred after removal of pouch young, the concentrations in pregnancies and failed pregnancies were similar; neither the timing of the early peak nor its magnitude were significantly different ( $P>0.05$ in both instances) (Tables 2 and 3).

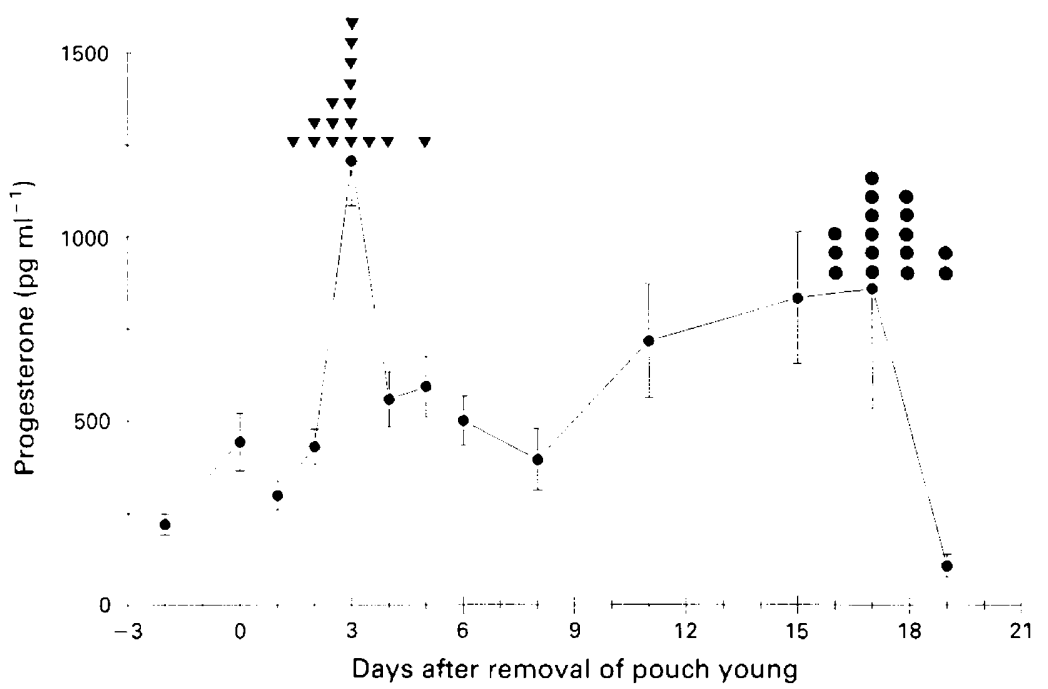

Fig. 1. Plasma progesterone concentrations for female Bettongia penicillata that underwent a pregnancy after removal of a pouch young. The progesterone values from day -2 to day 6 have been aligned on the mean day of the peak (day $3, n=16$ ); from day 8 to day $19, n=7$. The days of the early peak $(\boldsymbol{\nabla})$ and birth $(\boldsymbol{O})$ for individual bettongs are shown. Data are means \pm SEM.

Table 3. Intervals from removal of pouch young to early progesterone peak for female Bettongia penicillata associated with or without males post partum

\begin{tabular}{lccccc}
\hline & Removal of & & \multicolumn{2}{c}{ Intervals from } \\
\cline { 5 - 6 } $\begin{array}{l}\text { Type of } \\
\text { male post partum }\end{array}$ & $\begin{array}{c}\text { No. of } \\
\text { cycles }\end{array}$ & $\begin{array}{c}\text { poung to } \\
\text { progesterone peak } \\
\text { (days) }\end{array}$ & $\begin{array}{c}\text { Magnitude of } \\
\text { progesterone peak } \\
\text { (days) }\end{array}$ & $\begin{array}{c}\text { Removal of } \\
\text { young to birth } \\
\text { (pg ml }{ }^{-1} \text { ) }\end{array}$ & $\begin{array}{c}\text { Progesterone } \\
\text { peak to birth } \\
\text { (days) }\end{array}$ \\
\hline Intact male & 16 & $2 \cdot 9 \pm 0 \cdot 2$ & $1206 \pm 121$ & $17 \cdot 4 \pm 0 \cdot 2$ & $14 \cdot 5 \pm 0 \cdot 1$ \\
& 8 & $3 \cdot 3 \pm 0 \cdot 4$ & $1281 \pm 103$ & Nil & NA \\
Vasectomized male & 3 & Nil & Nil & Nil & Nil \\
No male present & 2 & $3 \cdot 7 \pm 0 \cdot 3$ & $886 \pm 150$ & NA & NA \\
& 12 & Nil & Nil & NA & NA \\
& 3 & $3 \cdot 7 \pm 0 \cdot 3$ & $1023 \pm 260$ & NA & NA \\
\hline
\end{tabular}

NA: not applicable.

Nil: observations made, but no events evident.

\section{Females associated with vasectomized males in the post partum period}

For six of eight females associated with a vasectomized male at post partum oestrus, after removal of pouch young the changes in plasma progesterone concentrations were not significantly 
different $(P>0.05)$ from changes seen in the pregnant and failed pregnant cycles (Table 3, Fig. 3). Two females in this group showed no increases in plasma progesterone concentrations after removal of pouch young.

\section{Females isolated from males in the post partum period}

On 12 of 15 occasions ( $n=13$ animals) there were no increases in plasma progesterone after removal of pouch young. Concentrations remained low to undetectable $\left(<100 \mathrm{pg} \mathrm{ml}^{-1}\right)$ and this has been defined as a nil response (Tables 1, 2 and 3). The exceptions occurred in two animals; in one of these, increases in plasma progesterone concentrations, typical of that described (Figs 1-4), were observed on both occasions after removal of pouch young. In the other animal, on one of two occasions, an increase in plasma progesterone concentration was detected after removal of pouch young.

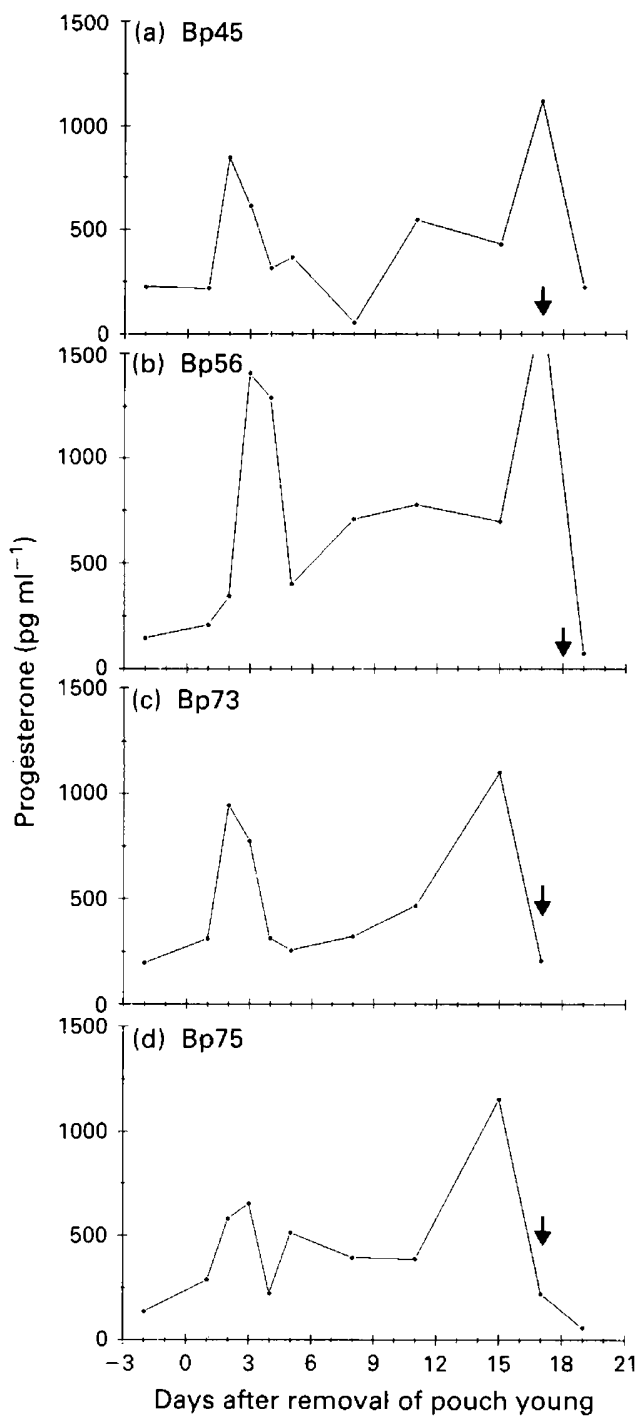

Fig. 2. Profiles of plasma progesterone during pregnancy for four female Bettongia penicillata. Arrows indicate day of birth of new pouch young. 


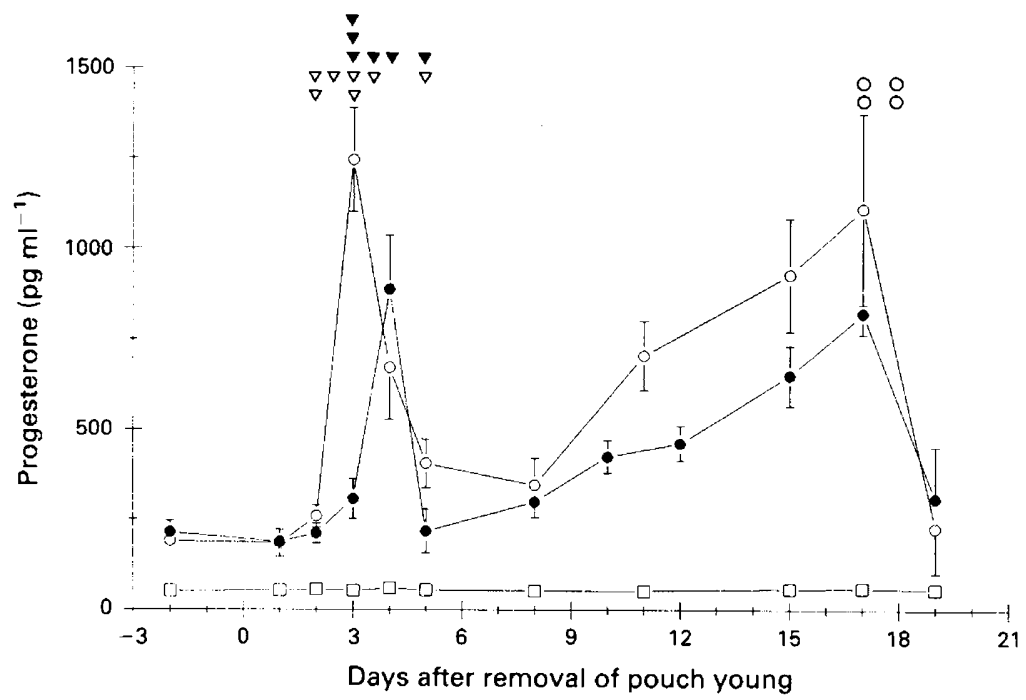

Fig. 3. Profiles of plasma progesterone after removal of pouch young for female Bettongia penicillata that, in the post partum period, were housed with intact males $(n=7)(0)$; vasectomized males $(n=6)(0)$; or isolated from males $(n=7)(\square)$. Values from days -2 to 5 have been aligned on the mean day of the early progesterone peak; individual peaks $(\nabla, \boldsymbol{\nabla})$ and births $(O)$ for the females when housed with intact males and vasectomized males, respectively. Data are means \pm SEM.

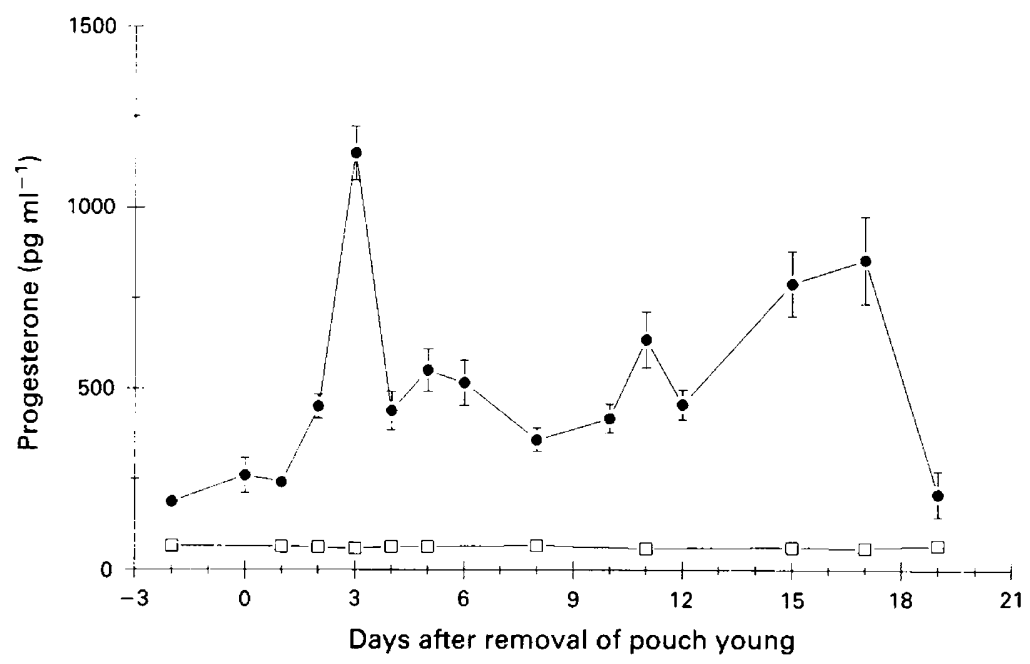

Fig. 4. Profiles of plasma progesterone concentration for all pregnant and nonpregnant cycles $(n=33)(-)$ and for all females showing no changes in progesterone concentration after removal of pouch young $(n=17)(\square)$. For days -2 to 6 after removal of pouch young values are aligned to the early progesterone peak, $n=33$, and for days 8 to $19, n=22$. Data are means \pm SEM. 


\section{Description of the profile of plasma progesterone}

Before removal of the pouch young the concentration of plasma progesterone was always less than $300 \mathrm{pg} \mathrm{ml}^{-1}$. Between days 2 and 5 after removal of pouch young, progesterone concentrations increased to an early peak ranging from $544 \mathrm{pg} \mathrm{ml}^{-1}$ to $2107 \mathrm{pg} \mathrm{ml}^{-1}$. For 16 pregnancies the day of this peak was $2 \cdot 9 \pm 0 \cdot 2$, and the magnitude was $1206 \pm 121 \mathrm{pg}$ progesterone $\mathrm{ml}^{-1}$ (Table 3, Fig. 1). For most animals the progesterone peak occurred on only one day, but, in some, the peak concentration occurred between two successive daily samples (Fig. 2, Table 2). The interval from the progesterone peak to birth was 14 or 15 days $(14 \cdot 3 \pm 0 \cdot 2)$ in all animals (Tables 2 and 3). After the early peak of progesterone the concentrations declined to about $400 \mathrm{pg} \mathrm{ml}^{-1}$ by day 8 but increased again to greater than $800 \mathrm{pg} \mathrm{ml}^{-1}$ from day 11 until parturition, at which time concentrations decreased to less than $200 \mathrm{pg} \mathrm{ml}^{-1}$. For six of seven animals, progesterone concentrations were low on the day or the day after a new young was detected in the pouch. For the remaining animal, plasma progesterone concentration was high on the day the young was found in the pouch (Fig. 2a), but had decreased by the following sample two days later (Figs 1 and 2).

Seven animals were monitored after isolation from males and after association with an intact, and a vasectomized, male. Only four of the females housed with intact males gave birth on day 17 or 18 (Fig. 3), but all showed typical progesterone profiles after removal of pouch young. When housed with the vasectomized males, six of the seven animals also cycled as described above. There were no significant differences between these reproductive states in the timing and magnitude of the plasma progesterone peak or in the increase of progesterone concentrations measured later in the cycles (Fig. 3, Table 2). However, when these females were isolated from males in the post partum period, plasma progesterone concentrations were $<100 \mathrm{pg} \mathrm{ml}^{-1}$ before removal of pouch young and remained at these concentrations after removal of pouch young (Fig. 3, Table 2).

Because there were no significant differences in the profiles of any pregnant, failed pregnant or nonpregnant cycles in which progesterone was increased after removal of pouch young, the results have been pooled $(n=33)$. Similarly, the results for all females $(n=17)$ that showed no changes in progesterone concentration after removal of pouch young have been combined (Fig. 4). The concentration of progesterone in this last group of females was always significantly different from that in females which cycled after removal of pouch young; i.e. before removal of pouch young, plasma progesterone was $225 \pm 23 \mathrm{pg} \mathrm{ml}^{-1}(n=30)$ in females that cycled, and $60 \pm 4 \mathrm{pg} \mathrm{ml}^{-1}(n=17)$ in those that did not $(P<0.001)$ (Fig. 4).

\section{Histology of ovaries and uteri}

No corpora lutea were found in the ovaries of two females isolated from males post partum, and in which plasma progesterone concentrations remained low $\left(<100 \mathrm{pg} \mathrm{ml}^{-1}\right)$ after removal of pouch young. These and other ovaries from nonlactating females isolated from males often contained several, large corpora albicantia, each similar in appearance, as well as many atretic follicles,

Fig. 5. Micrographs of luteal tissue and uterine glands from Bettongia penicillata. (a) Quiescent corpus luteum: luteal cells are small, with regular, round, small nuclei $(\times 520)$. (b) Corpus albicans: the luteal cells are indiscrete and the nuclei are large and irregularly shaped $(\times 520)$. (c) Transverse section of uterine glands from a female in lactational quiescence. The gland cells are high columnar with rounded nuclei mostly basal. The lining of the uterine lumen consists of ciliated and nonciliated cells. Round and elongate nuclei are found at various levels in these cells $(\times 330)$. (d) Transverse section of uterine glands from a female isolated from males post partum. No corpus luteum was present in the ovaries, only corpora albicantia. The uterine glands were small and lined with low columnar epithelium with basal nuclei that were slightly elongate. No ciliated cells were seen lining the uterine lumen; these cells were cuboidal and contained oval nuclei that occupied almost all of the cell $(\times 330)$. 


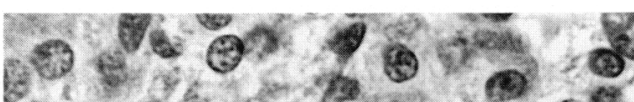
- 0028.5 $130^{\circ}$

- 80,300 Q 002 .

at 9 है 5 5. ${ }^{\circ}, x^{2} 5^{\circ}$ - 10.50. 120 . - cos es a - 50.0 .520 $18 \%$

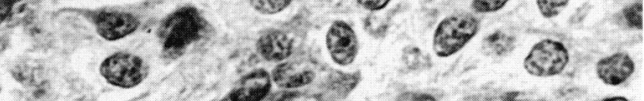
so 550.5 a $0^{3} 20^{3}$

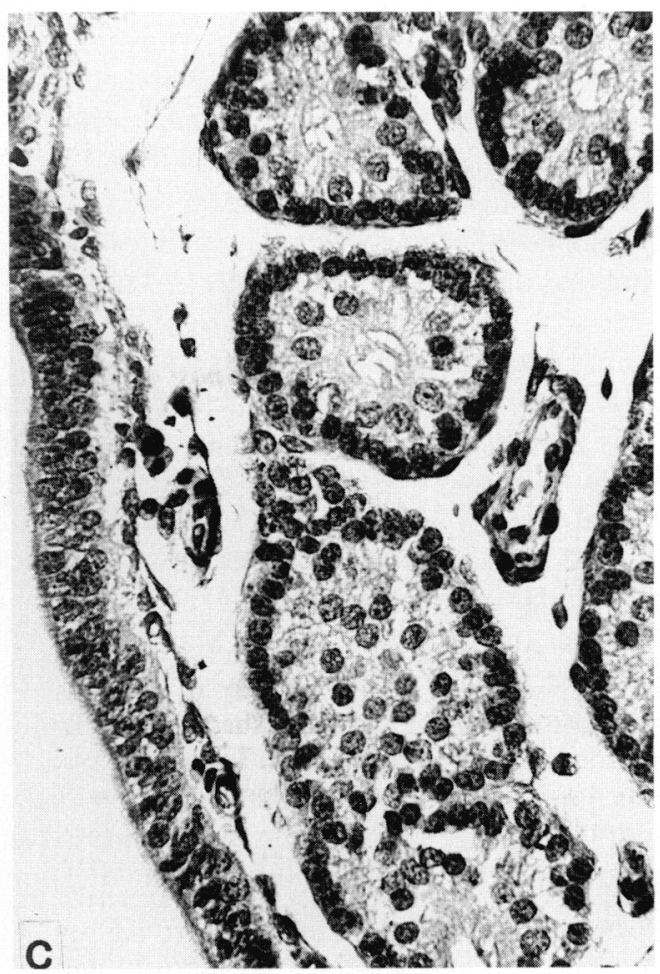

$5+a^{\circ} \theta^{\circ} \cdot \theta^{2}, 9$ 3 . 100090 $\rightarrow 0000 \%$ - $\theta \cdot 0^{2} \cdot 2$. - C.8 0 की 36.6. की $40^{\circ}-4000$

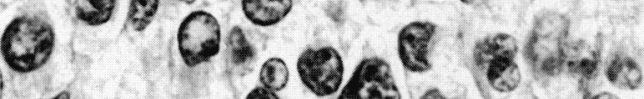

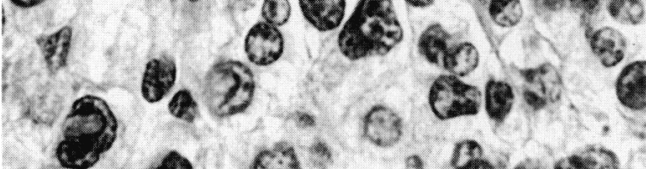
- $28 \%$ क 800

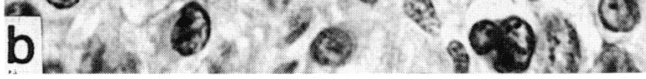

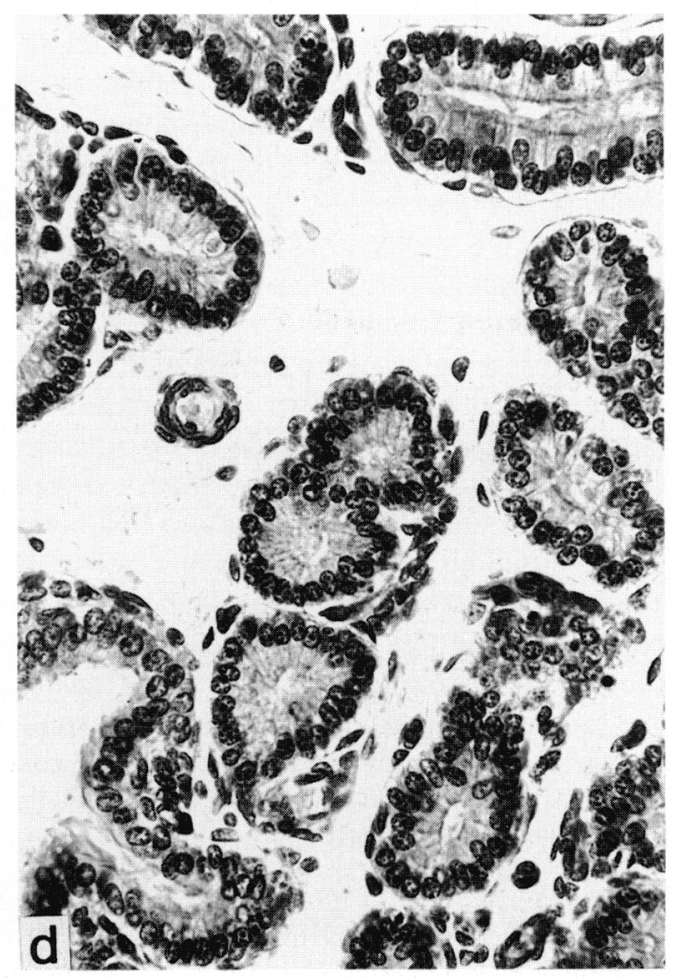


but none contained corpora lutea. The cells of the corpora albicantia were larger than those of a quiescent corpus luteum (Fig. 5a, b) and the nuclei were larger and more irregular in shape. The uterine glands of these females were small and sparse and lined with low columnar epithelium, in contrast to the uterine glands of a female that had a quiescent corpus luteum on one ovary (Fig. 5c, d).

\section{Discussion}

The major finding of the present study is that brush-tailed bettongs are induced ovulators; the presence of the male post partum is important for follicular growth, ovulation or both and the formation of a new corpus luteum. Removal of the pouch young from most females isolated from males post partum is not followed by an increase in plasma progesterone concentration, and their ovaries do not contain a corpus luteum. This is the first observation of induced ovulation within the superfamily Macropodoidea, a taxon in which it has always been assumed from studies of other member species that ovulation occurs spontaneously. However, from this study it is not possible to determine whether a stimulus from pheromones alone is essential to induce ovulation, as has been described for several eutherian species (Whitten, 1966; Milligan, 1980), or whether copulation itself is required for ovulation to occur. Induced ovulation due to pheromonal signals has been reported for only one other marsupial, the grey short-tailed opossum, Monodelphis domestica, of South America; the presence of a strange male or his odours stimulates reproductive activity in females (Fadem et al., 1982; Fadem \& Rayve, 1985; Fadem, 1985, 1987, 1989; Hinds et al., 1992). As in $B$. penicillata, the profiles of plasma progesterone concentration were similar for female $M$. domestica paired with intact or vasectomized males, but no changes in plasma progesterone indicative of active corpora lutea were seen in females isolated from males (Hinds et al., 1992).

Although several female brush-tailed bettongs ovulated spontaneously, even when totally isolated from males, for most females the presence of a male is required for a return to oestrus and ovulation. In a separate study (Smith, 1992), females, isolated from males before parturition, were housed with a male on the day of removal of pouch young and the return to oestrus in the females was determined. Under the conventional macropodid premise, if a quiescent corpus luteum was present, the time to return to oestrus would be approximately the same as the interval from a fertile mating to post partum oestrus, that is $>17.5$ days. However, in these females, the time to return to oestrus was $6.6 \pm 0 \cdot 26$ days (mean $\pm \mathrm{SEM} ; n=9$ ) after removal of the pouch young (Smith, 1992), suggesting that no corpus luteum had been present and that the presence of the male had stimulated this early return to oestrus.

The absence of a corpus luteum in the ovaries of unmated, isolated female bettongs (this study) was confirmed by histology, and correlated with the significantly lower progesterone concentrations in these females. Further, their uterine glands were inactive and similar in appearance to those of eastern grey kangaroos, Macropus giganteus, during anoestrus (Clark \& Poole, 1967). The ovaries without a corpus luteum also had many more atretic than normal follicles compared with those containing a quiescent corpus luteum. Large numbers of atretic follicles have also been observed in Marmosa robinsoni undergoing short anovular cycles (Godfrey, 1975), and in one specimen of the tree kangaroo (Dendrolagus) which was isolated from males (Mathews, 1947). Another interesting feature of ovaries from $B$. penicillata was the number of corpora albicantia (one to five) retained; each was large and similar in appearance, rather than at differing stages of degeneration as would be expected of luteal tissue formed at successive oestrous periods.

The plasma progesterone profile in B. penicillata is bimodal as it is in the family Macropodidae; there is an early peak of progesterone concentration of similar magnitude to the concentration seen towards the end of the cycle. The circulating concentrations are higher than in the tammar (Hinds and Tyndale-Biscoe, 1982) and Bennett's wallaby (Walker \& Gemmell, 1983; Curlewis et al., 1987), but similar to those observed in quokkas (Cake et al., 1980) and two B. gaimardi (Rose, 1989). Like the tammar and Bennett's wallaby, but in contrast to the quokka, the early progesterone peak in $B$. 
penicillata occurs in both pregnant and nonpregnant cycles. In addition, although the early peak of progesterone concentration occurred in individual bettongs on different days after removal of pouch young ( $2-5$ days), the interval from the peak to birth was consistently 14 or 15 days. Thus, as has been suggested for the tammar (Tyndale-Biscoe \& Hinds, 1989), the early peak is probably important for stimulating uterine gland development and secretion, and may synchronize development of the newly activated blastocyst. Because there were no significant differences in the timing or magnitude of the early progesterone peak in female bettongs that underwent a cycle (whether pregnant or nonpregnant), there would appear to be no influence of the embryo on early luteal function as suggested for the quokka by Cake et al. (1980). Hinds \& Tyndale-Biscoe (1982) reported that the peak was slightly higher in pregnancy than in the oestrous cycle for the same animals $(n=5)$, but subsequent studies involving many more tammars show no significant differences due to reproductive state (Tyndale-Biscoe et al., 1986; Tyndale-Biscoe \& Renfree, 1987; Tyndale-Biscoe et al., 1988; Hinds, 1989a, 1990). In the light of the results for the tammar, Bennett's wallaby and brush-tailed bettong, the studies in the quokka should be repeated to confirm or refute the absence of the early peak and establish whether there are significant differences in its magnitude or timing in the two reproductive states.

This study established that another species of the superfamily Macropodoidea shows a bimodal pattern of plasma progesterone during pregnancy and the oestrous cycle. The more significant finding, however, is that $B$. penicillata does not ovulate spontaneously as has been accepted for all Australian marsupials. More detailed observations of other Australian marsupials may reveal other species that are induced ovulators. One species which warrants further examination is the tree kangaroo, Dendrolagus, in which the ovaries of one zoo specimen contained many atretic follicles, but no normal luteal tissue (Mathews, 1947).

We thank B. Hancl and C. Horne for assistance with care of the bettongs and collection of blood samples. The vasectomies were performed by $\mathrm{C}$. H. Tyndale-Biscoe who also provided valuable criticism of the manuscript. J. Wright assisted with the progesterone assays, and G. Chapman prepared the photographs. Financial assistance for the bettong colony was provided by an ARC grant to M. J. Smith.

\section{References}

Cake, M.H., Owen, F.J. \& Bradshaw, S.D. (1980) Difference in concentration of progesterone in the plasma between pregnant and non-pregnant quokkas (Setonix brachyurus). Journal of Endocrinology 84, $153-158$.

Clark, M.J. \& Poole, W.E. (1967) The reproductive system and embryonic diapause in the female grey kangaroo, Macropus giganteus. Australian Journal of Zoolog. 15, 441-459.

Curlewis, J.D., White, A.S. \& Loudon, A.S.I. (1987) The onset of seasonal quiescence in the female Bennett's wallaby (Macropus rufogriseus rufogriseus). Journal of Reproduction and Fertility 80, 119-124.

Fadem, B.H. (1985) Evidence for the activation of female reproduction by males in a marsupial, the gray shorttailed opossum (Monodelphis domestica). Biology of Reproduction 33, 112-116.

Fadem, B.H. (1987) Activation of estrus by pheromones in a marsupial: stimulus control and endocrine factors. Biology of Reproduction 36, 328-332.

Fadem, B.H. (1989) The effects of pheromonal stimuli on estrus and peripheral plasma estradiol in female gray short-tailed opossums (Monodelphis domestica). Biology of Reproduction 41, 213-217.
Fadem, B.H. \& Rayve, R.S. (1985) Characteristics of the oestrous cycle and influence of social factors in grey short-tailed opossums (Monodelphis domestica). Journal of Reproduction and Fertility 73, 337-342.

Fadem, B.H., Trupin, G.L., Maliniak, E., VandeBerg, J.L. \& Hayssen, V. (1982) Care and breeding of the gray, short-tailed opossum (Monodelphis domestica). Laboratory Animal Science 32, 405-409.

Godfrey, G.K. (1975) A study of oestrus and fecundity in a laboratory colony of Mouse opossums (Marmosa robinsoni). Journal of Zoology 175, 541-555.

Hinds, L.A. (1989a) Morning pulse of prolactin maintains seasonal quiescence in the tammar, Macropus eugenii. Journal of Reproduction and Fertility 87, $735-744$.

Hinds, L.A. (1989b) Plasma progesterone through pregnancy and the estrous cycle in the eastern quoll, Dasyurus viverrinus. General and Comparative Endocrinology 75, 110-117.

Hinds, L.A. (1990) Control of pregnancy, parturition and luteolysis in marsupials. Reproduction Fertility and Development 2, 535-552.

Hinds, L.A. \& Tyndale-Biscoe C.H. (1982) Plasma progesterone levels in the pregnant and non-pregnant 
tammar Macropus eugenii. Journal of Endocrinology 93, 99-107.

Hinds, L.A., Reader, M., Wernberg-Moller, S. \& Saunders, N.R. (1992) Hormonal evidence for induced ovulation in Monodelphis domestica. Journal of Reproduction and Fertility 95, 303-312.

Mathews, L.H. (1947) A note on the female reproductive tract in the tree kangaroo (Dendrolagus). Proceedings of the Zoological Society of London 117, 313-333.

Milligan, S.R. (1980) Pheromones and rodent reproductive physiology. Symposia of the Zoological Society of London 45, 251-275.

Parker, P. (1977) An ecological comparison of marsupial and placental patterns of reproduction. In The Biology of Marsupials, pp. 273 286. Eds B. Stonehouse \& D. Gilmore. Macmillan, London.

Rose, R.W. (1989) Reproductive biology of ratkangaroos. In Kangaroos, Wallabies and Ratkangaroos, pp. 307 315. Eds G. Grigg, P. Jarman \& I. Hume. Surrey Beatty \& Sons Pty Ltd, Sydney.

Sernia, C., Hinds, L.A. \& Tyndale-Biscoe, C.H. (1980) Progesterone metabolism during embryonic diapause in the tammar wallaby, Macropus eugenii. Journal of Reproduction and Ferility 69, 139-147.

Smith, M.J. (1992) Evidence from the oestrous cycle for male-induced ovulation in Bettongia penicillata (Marsupialia). Journal of Reproduction and Fertility 95, 283-289.

Tyndale-Biscoe, C.H. \& Hinds, L.A. (1989) The hormonal milieu during early development in marsupials.
In Development of Preimplantation Embryos and Their Environment, pp. 237-246. Eds K. Yoshinaga \& T. Mori. Alan R. Liss, Inc., New York.

Tyndale-Biscoe, C.H.\& Renfree, M.B.(1987) Reproductive Physiology of Marsupials. Cambridge University Press, Cambridge, UK.

Tyndale-Biscoe, C.H., Hinds, L.A., Horn, C.A. \& Jenkin, G. (1983) Hormonal changes at oestrus, parturition and post-partum oestrus in the tammar wallaby (Macropus eugenii). Journal of Endocrinology 96, 155-161.

Tyndale-Biscoe, C.H., Hinds, L.A. \& McConnell, S.J. (1986) Seasonal breeding in a marsupial: opportunities of a new species for an old problem. Recent Progress in Hormone Research 42, 471-512.

Tyndale-Biscoe, C.H., Hinds, L.A. \& Horn, C.A. (1988) Fetal role in the control of parturition in the tammar, Macropus eugenii. Journal of Reproduction and Fertility 82, 419-428.

Walker, M.T. \& Gemmell, R.T. (1983) Plasma concentrations of progesterone, oestradiol-17 $\beta$ and 13,14dihydro-15-oxo-prostaglandin $\mathrm{F} 2 \alpha$ in the pregnant wallaby (Macropus rufogriseus rufogriseus). Journal of Endocrinology 97, 369-377,

Whitten, W.K. (1966) Pheromones and mammalian reproduction. Advances in Reproductive Physiology 1, $155-177$.

Received 30 May 1991 